DOI: 10.1111/all.14787

ORIGINAL ARTICLE

Asthma and Lower Airway Disease

\title{
Childhood asthma outcomes during the COVID-19 pandemic: Findings from the PeARL multinational cohort
}

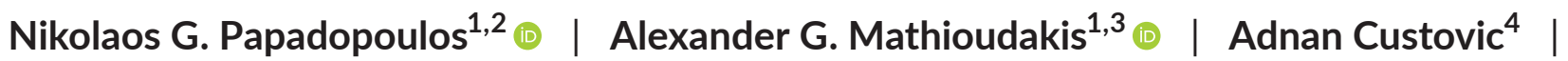 \\ Antoine Deschildre $^{5}$ ๑) | Wanda Phipatanakul ${ }^{6}$ | Gary Wong ${ }^{7}$ (i) \\ Paraskevi Xepapadaki $^{2}$ ( ) | Rola Abou-Taam ${ }^{8}$ | loana Agache ${ }^{9}$ (i) | \\ Jose A. Castro-Rodriguez ${ }^{10}$ | Zhimin Chen ${ }^{11}$ (0) | Pierrick Cros ${ }^{12}$ \\ Jean-Christophe Dubus $^{13}$ | Zeinab Awad El-Sayed ${ }^{14}$ | Rasha El-Owaidy ${ }^{14}$ (ㅇ | \\ Wojciech Feleszko ${ }^{15}$ (c) | Vincenzo Fierro ${ }^{16}$ | Alessandro Fiocchi ${ }^{16}$ \\ Luis Garcia-Marcos $^{17,18}$ | Anne Goh ${ }^{19}$ | Elham M. Hossny ${ }^{14}$ |
} Yunuen R. Huerta Villalobos ${ }^{20}$ | Tuomas Jartti ${ }^{21}$ | Pascal Le Roux ${ }^{22}$ | Julia Levina ${ }^{23}$ | Aida Inés López García ${ }^{24}$ | Ángel Mazón Ramos ${ }^{25}$ | Mário Morais-Almeida ${ }^{26}$ | Clare Murray $^{1}$ | Karthik Nagaraju ${ }^{27}$ | Major K. Nagaraju ${ }^{28}$ | Elsy Maureen Navarrete Rodriguez ${ }^{29}$ | Leyla Namazova-Baranova ${ }^{23,30}$ | Antonio Nieto Garcia ${ }^{25}$ | Cesar Fireth Pozo Beltrán ${ }^{31,32}$ | Thanaporn Ratchataswan ${ }^{6}$ | Daniela Rivero Yeverino $^{33}$ | Eréndira Rodríguez Zagal ${ }^{20}$ | Cyril E. Schweitzer ${ }^{34}$ | Marleena Tulkki $^{35}$ | Katarzyna Wasilczuk ${ }^{15}$ | Dan $\mathrm{Xu}^{11}$ | PeARL collaborators, on behalf of the PeARL Think Tank

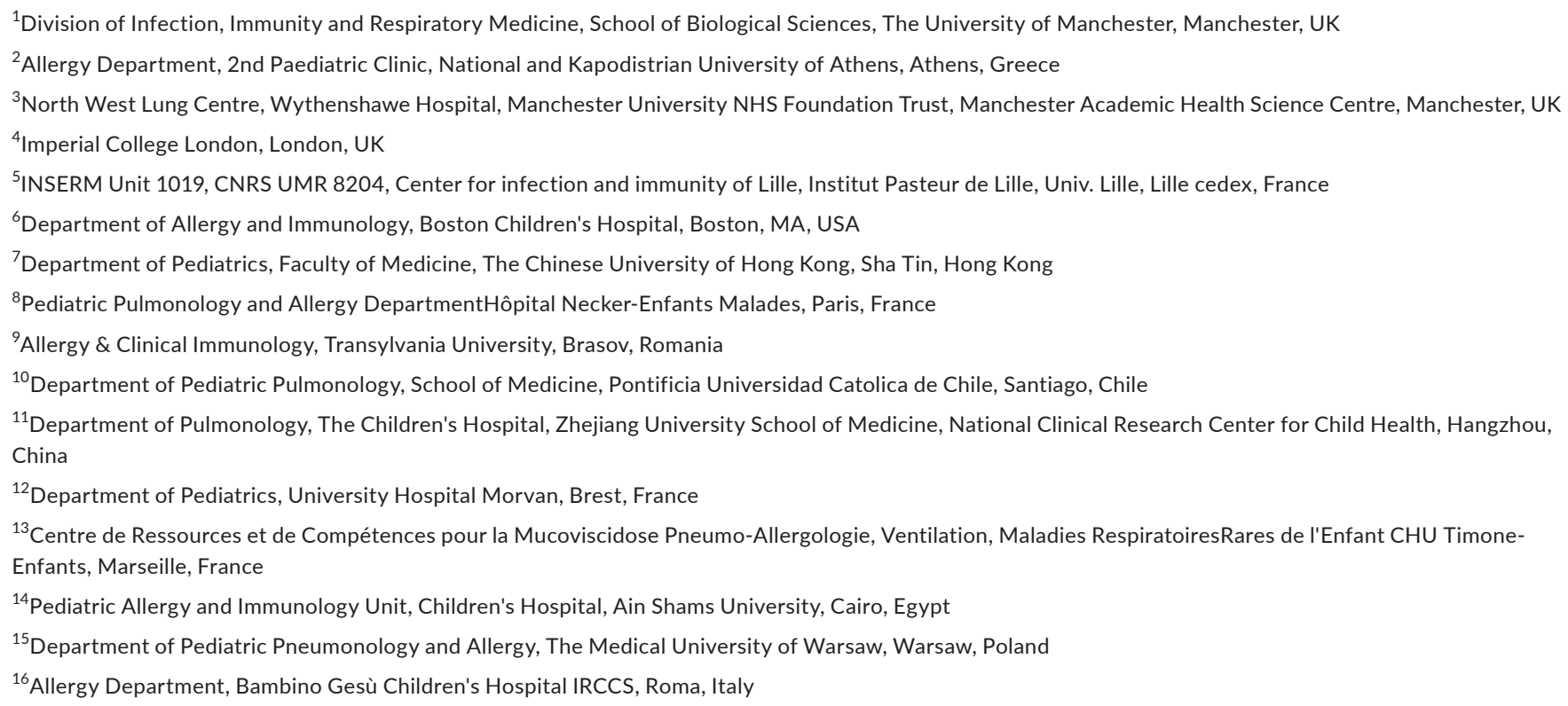


${ }^{17}$ Pediatric Respiratory and Allergy Units, "Virgen de la Arrixaca" Children's University Clinical Hospital, University of Murcia, Murcia, Spain

${ }^{18}$ Institute for Biomedical Research of Murcia, IMIB-Arrixaca; \& Network of Asthma and Adverse and Allergic Reactions ARADyAL, Murcia, Spain

${ }^{19}$ Department of Internal Medicine, Rush Medical College, Chicago

${ }^{20}$ Hospital General Regional 1 "Dr. Carlos Mac Gregor Sánchez Navarro" IMSS, Mexico, Mexico

${ }^{21}$ Department of Pediatrics and Adolescent Medicine, Oulu University Hospital and University of Oulu, Oulu, Finland

${ }^{22}$ Department of Pediatrics, Groupe Hospitalier Le Havre, Le Havre, France

${ }^{23}$ Pediatric and Child Health Research Institute of the Central Clinical Hospital of the Russian Academy of Sciences, Moskva, Russia

${ }^{24}$ Allergy and Clinical Immunology Service of the University Hospital of Puebla, Puebla, Mexico

${ }^{25}$ Pediatric Pulmonology \& Allergy Unit Children's Hospital la Fe, Valencia, Spain

${ }^{26}$ Allergy Center, CUF Descobertas Hospital, Lisbon, Portugal

${ }^{27}$ VN Allergy \& Asthma Research Centre, Chennai, India

${ }^{28}$ Department of Allergy \& Clinical Immunology, Saveetha Medical College, Chennai, India

${ }^{29}$ Pediatric Allergy and Clinical Immunology Service, Hospital Infantil, til de Mexico Federico Gómez, Mexico City, Mexico

${ }^{30}$ Pirogov Russian National Research Medical University of the Ministry of Health of the Russian Federation, Moscow, Russia

${ }^{31}$ Teaching and Research Department and Paediatric Allergy Department, Hospital with Specialties Juan María de Salvatierra, La Paz, Mexico

${ }^{32}$ Allergy \& immunology Department Hospital Infantil de Medico Federico Gomez, Mexico City, Mexico

${ }^{33}$ Allergy and Clinical Immunology Department, Hospital Universitario de Puebla, Puebla, Mexico

${ }^{34} \mathrm{CHRU}$ de Nancy, Hôpitald'Enfants, Vandoeuvre, France

${ }^{35}$ Department of Pediatrics and Adolescent Medicine, Turku University Hospital and University of Turku, Turku, Finland

\section{Correspondence}

Nikolaos G. Papadopoulos, University of Manchester, Oxford Rd, Manchester M13 9PL, UK.

Email: ngpallergy@gmail.com

\author{
Abstract \\ Background: The interplay between COVID-19 pandemic and asthma in children is \\ still unclear. We evaluated the impact of COVID-19 pandemic on childhood asthma \\ outcomes.
}

Methods: The PeARL multinational cohort included 1,054 children with asthma and 505 non-asthmatic children aged between 4 and 18 years from 25 pediatric departments, from 15 countries globally. We compared the frequency of acute respiratory and febrile presentations during the first wave of the COVID-19 pandemic between groups and with data available from the previous year. In children with asthma, we also compared current and historical disease control.

Results: During the pandemic, children with asthma experienced fewer upper respiratory tract infections, episodes of pyrexia, emergency visits, hospital admissions, asthma attacks, and hospitalizations due to asthma, in comparison with the preceding year. Sixty-six percent of asthmatic children had improved asthma control while in $33 \%$ the improvement exceeded the minimal clinically important difference. Prebronchodilatation $\mathrm{FEV}_{1}$ and peak expiratory flow rate were improved during the pandemic. When compared to non-asthmatic controls, children with asthma were not at increased risk of LRTIs, episodes of pyrexia, emergency visits, or hospitalizations during the pandemic. However, an increased risk of URTIs emerged.

Conclusion: Childhood asthma outcomes, including control, were improved during the first wave of the COVID-19 pandemic, probably because of reduced exposure to asthma triggers and increased treatment adherence. The decreased frequency of acute episodes does not support the notion that childhood asthma may be a risk factor for COVID-19. Furthermore, the potential for improving childhood asthma outcomes through environmental control becomes apparent.

KEYWORDS

childhood asthma, coronavirus, COVID-19 


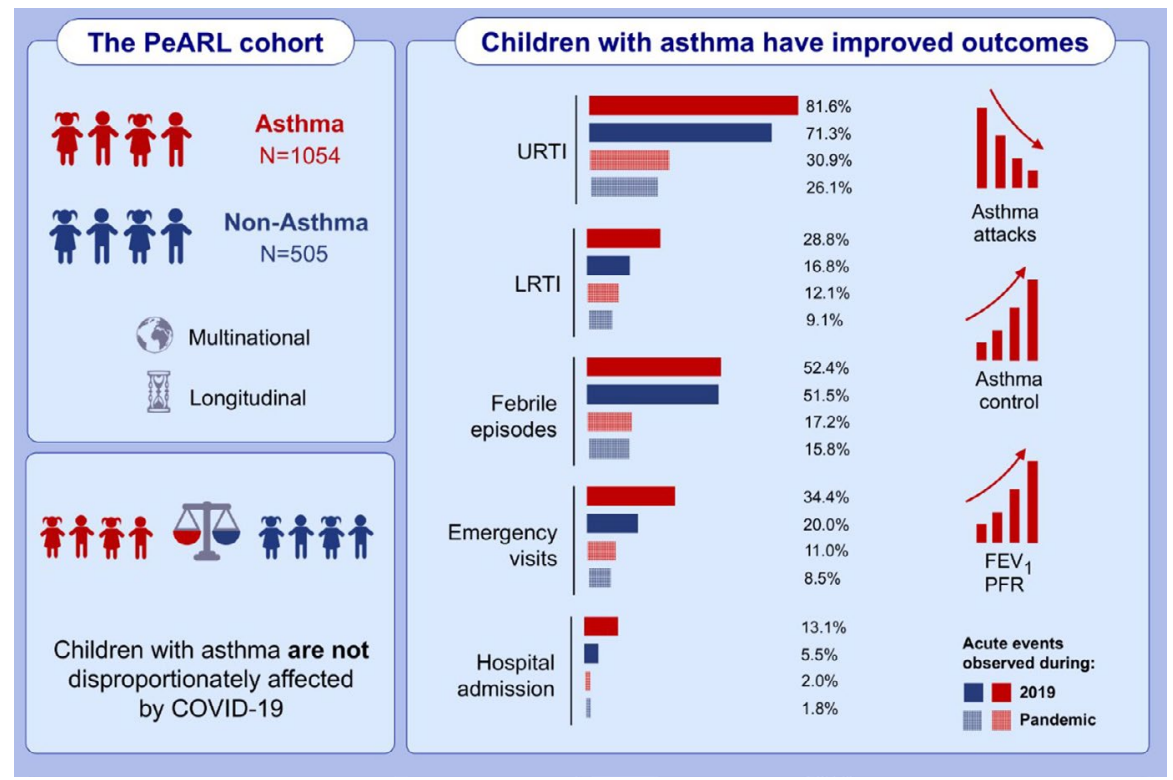

\section{GRAPHICAL ABSTRACT}

This study evaluates the frequency of acute respiratory and febrile presentations furing the first wave of COVID-19 pandemic in childhood asthma. Data from the multinational PeARL cohort reveal improved health and asthma activity during the first wave of the COVID-19 pandemic, probably attributed to decreased exposure to asthma triggers and increased treatment adherence. During that period, children with asthma experienced fewer URTIs, episodes of pyrexia, emergency visits, hospital admissions, asthma attacks and hospitalizations due to asthma, in comparison to the preceding year.

\section{1 | INTRODUCTION}

A series of studies have demonstrated that the morbidity from Coronavirus Disease 2019 (COVID-19) is lower in children compared to adults. ${ }^{1-3}$ Risk factors for severe disease include older age, male sex, chronic respiratory diseases, diabetes, coronary artery disease, obesity, and ethnicity (black, Asian, and mixed). ${ }^{4-6}$ Chronic respiratory diseases are among these high-risk pre-existing conditions, and asthma represents the majority of such patients. ${ }^{4,5,7}$ Initial clinical reports did not identify asthma to be over-represented among COVID-19 patients, $^{8}$ but severe, uncontrolled asthma is included in most guidance documents among conditions which may increase the risk for severe COVID-19. ${ }^{9}$ Analysis in more than 17 million adults and 11,000 COVID-19-related deaths identified severe asthma (defined as asthma with recent oral corticosteroid use) as a significant associate of COVID-19 death6. It is, however, unclear what is the impact of asthma on the risk of SARS-CoV-2 infection and severeCOVID-19 in children, and what is the impact of COVID-19 pandemic on asthmarelated outcomes in children. Survey data among pediatric asthma specialists suggest that there is no apparent increase in asthmarelated morbidity in children with asthma ${ }^{10}$; it is even possible that due to increased adherence and reduced exposures due to confinement, such children may have improved outcomes. ${ }^{10}$ Furthermore, it is also possible that allergic sensitization can have some protective effect against COVID-19. ${ }^{11}$ However, this needs to be further explored. ${ }^{12,13}$

For the above reasons, Pediatric Asthma in Real Life (PeARL), a think tank initiated by the Respiratory Effectiveness Group (REG), comprising of pediatric asthma experts globally, ${ }^{14}$ opted to evaluate the interplay between childhood asthma and the pandemic due to COVID-19 infection in a multinational cohort of children with asthma and non-asthmatic controls. We aimed at assessing asthma activity (asthma control, respiratory infections, asthma attacks, and lung function) during the first months of the COVID-19 pandemic and exploring whether children with asthma had excess morbidity during this period, in comparison with prerecorded historical data.

The primary study objective was to assess differences in the impact of the pandemic on the frequency of upper (URTIs), lower respiratory tract infections (LRTIs), episodes of fever, emergency visits, and hospital admissions between asthmatic and non-asthmatic children. Secondary objectives to evaluate were as follows: (i) the impact of the pandemic on the frequency of asthma attacks, as well as the previously mentioned events among asthmatic children, compared to the baseline frequency of these events, during the preceding year (2019); (ii) the impact of the pandemic on disease control, evaluated using validated asthma clinical questionnaires, among children with asthma, compared to the baseline asthma control, during the preceding year (2019).

\section{2 | METHODS}

\section{1 | Study design, setting, and participants}

The impact of the COVID-19 pandemic on disease activity in children with asthma was evaluated in data collected as part of a multinational audit. Ethics review was not required for this audit, in most participating countries. When required, an ethics approval was acquired. The cross-sectional case-control study was designed and managed by 
the PeARL Steering Committee, was conducted in accordance with the Good Clinical Practice Guidelines and reported following the Strengthening the reporting of observational studies in epidemiology (STROBE) statement. ${ }^{15}$ Participating centers were identified among members and collaborators of the PeARL think tank.

\subsection{Eligibility criteria, sources, and methods of selection of participants}

Eligible subjects were children aged between 4 and 18 years, diagnosed with asthma and monitored in one of the participating asthma clinics. Non-asthmatic controls included children of the same age range, monitored at the same healthcare setting for a non-respiratory condition, who did not clinically suffer from asthma. Children with other chronic respiratory conditions, diabetes, hypertension, immunodeficiency, or any other chronic disease deemed by the responsible clinician that could impact the main outcomes of this study, were excluded. Each participating center was asked to contribute data from at least 45 participants, including twice as many children with asthma, compared to controls.

\section{3 | Definition of variables}

For the purposes of this study, the onset of the pandemic in each participating center was defined as the date of the first fatality due to COVID-19 in the respective country. For each participant, the duration of the pandemic period was defined as the period between the onset of the pandemic and the captured clinical visit. Historical data (before the pandemic) were captured during 2019 and the duration of observation before the onset of the pandemic was 1 year, for all participants.

We collected basic demographic data for all participants and data on the main outcomes of interest. The frequency of acute events (URTIs, LRTIs, asthma attacks, episodes of fever, emergency visits, for any reason, and hospital admissions, for any reason) during and before the pandemic was reported as recalled by the participants or their parents. URTIs included episodes of sore throat, pharyngitis, or rhino/sinusitis. LRTIs included episodes associated acute bronchitis or pneumonia and were differentiated from URTIs on the basis of the clinical presentation. Asthma attacks were defined as the need for systemic glucocorticoids administration for at least $48 \mathrm{~h}$ or an emergency visit or a hospitalization for asthma. Need for additional treatment was defined as any treatment escalation, including increased use of short-acting bronchodilators, increased dose of inhaled corticosteroids, or the administration of systemic corticosteroid courses. Asthma activity during and before the pandemic was measured using validated disease control questionnaires (asthma control test: $\mathrm{ACT},{ }^{16}$ childhood asthma control test: $\mathrm{C}-\mathrm{ACT},{ }^{17}$ asthma control questionnaire: $\mathrm{ACQ},{ }^{18}$ or composite asthma severity index: $\mathrm{CASI}^{19}$ ). For each participant with asthma, at least one questionnaire was administered at least 2 months after the onset of the pandemic in their country and at least once during 2019 (the same questionnaire in both occasions). Physiological measurements, including forced expiratory value in 1 second $\left(\mathrm{FEV}_{1}\right)$, before or after bronchodilation and the peak expiratory flow rate (PFR), during and before the pandemic, were also captured when available.

\subsection{Statistical analysis}

Statistical analyses were performed using R statistical software (version 3.4.3 or newer; R Foundation for Statistical Computing; Vienna; Austria). We did not perform power calculations, as this was an exploratory analysis. Shapiro-Wilk test was used to evaluate normality of the distribution of continuous data. Student's t-test and MannWhitney test were used for comparing means of normally or nonnormally distributed variables, respectively. Chi-squared test was used for comparing dichotomous data. The level of significance was set at 0.05 for all analyses.

We used a generalized linear model for evaluating the impact of the pandemic on the frequency of acute events in asthmatic versus non-asthmatic participants. We assumed a negative binomial distribution, with the number of events during the pandemic as the response variable and the natural logarithm of the duration of the pandemic for each participant as an offset variable. We included as potential covariates the age, gender, and the number of acute events each participant experienced during 2019, race (if it was available, according to the participating countries' ethics regulations), passive smoking history (cigarettes smoked per day by the parents), concomitant known history of allergic rhinitis, clinically relevant IgE sensitization, food allergy and history of flu vaccination during the preceding year. These variables were considered the most pertinent by the study group.

For evaluating the impact of the pandemic on the frequency of each acute event in asthmatic and non-asthmatic children, we extrapolated an annualized event count based on the number of observed events during the pandemic ( $365^{*}$ events/pandemic duration [in days]). We then compared this with the actual number of acute events observed during 2019 using the Wilcoxon signed-rank test. In addition, we present the number of participants who had at least one event during the pandemic and during the preceding year.

Wilcoxon signed-rank test was also used to assess the impact of the pandemic on asthma control. As previously described, different standardized measures of asthma control were used in each center, depending on the measures that were evaluated during 2019, to facilitate comparisons. Firstly, we compared asthma control during versus before the pandemic in subgroups of participants, depending on the available asthma control tools. Next, we used Z-scores to estimate standardized differences by dividing the differences in the values during versus before the pandemic, with the standard deviation of all differences, for every test. In a sensitivity analysis, we only included subjects with a previous asthma control assessment between March and June 2019, during the same period as the pandemic, to account for seasonal variation. 
Paired $t$ test was used to compare pulmonary function measurements during versus before the pandemic. As previously, we conducted a sensitivity analysis only including subjects with a previous pulmonary function test, between March and June, 2019.

Finally, in a subgroup analysis, we repeated all previously described analyses only including data from participating centers that are in countries that were more severely hit by the pandemic $(>200$ deaths per million of inhabitants by 13/07/2020).

\section{3 | RESULTS}

\section{1 | Participants and descriptive data}

The study included 1,054 children with asthma and 505 control subjects, from 25 pediatric departments from 15 countries globally (Table S1). The baseline characteristics of the participants were generally balanced between the groups with a few, anticipated exceptions (Tables 1 and 2). A higher proportion of males (62.8\% versus $51.9 \%$ ) was observed in the asthma group compared to the controls, which is consistent with epidemiological characteristics of the disease in this age group. Allergic diseases such as allergic rhinitis $(79.4 \%$ vs $39.4 \%$ ) and food allergy (22.8\% vs $15.6 \%$ ) were also more prevalent in the asthma group. A higher proportion of children with asthma had a confirmed IgE sensitization and was vaccinated for the flu in the preceding year. Finally, children with asthma suffered a higher number of episodes of URTIs, LRTIs, emergency visits, or hospital admissions during 2019, compared to the control group (Tables 3 and 4).

National lockdowns were imposed in all participating countries apart from Finland and Hong Kong Lockdown measures were in place for a median of $54.5 \%$ (quantiles $27.8 \%-76.7 \%$ ) of the study period days. Moreover, schools were closed for the duration of the study period in over half of the participating centers (median 100\%, quantiles: $57.7 \%-100 \%)$

\section{2 | Outcome data}

\subsection{1 | Acute events frequency among asthmatic} versus non-asthmatic controls during the pandemic

Using generalized linear regression analysis, we evaluated betweengroup differences in the frequency of acute events during COVID-19 pandemic (Tables 3 and 4). Children with asthma were not found to be at increased risk of LRTIs, episodes of pyrexia, emergency visits, or hospitalizations during the pandemic. However, our analyses revealed an increased risk of URTI among children with asthma, compared to the control group, during the pandemic ( $p=0.005)$.
TABLE 1 Main characteristics of the participants. Continuous data are presented as median [percentiles 25-75], total number of participants with available data for this variable, and dichotomous data as number of events/ total numbers (percentage)

\begin{tabular}{|c|c|c|c|}
\hline & Cases & Controls & $p$-value \\
\hline Number of participants, $N$ & 1054 & 505 & \\
\hline $\begin{array}{l}\text { Observation during the pandemic } \\
\text { (days) }\end{array}$ & 102 [77-123] & 102 [79-122] & 0.68 \\
\hline Age (years) & $10[8-12]$ & 10 [8-13] & 0.42 \\
\hline Sex (female) & $392(37.2 \%)$ & $243(48.1 \%)$ & $<0.001$ \\
\hline \multicolumn{4}{|l|}{ Race } \\
\hline Asian & $111(10.5 \%)$ & $53(10.5 \%)$ & 0.1 \\
\hline Black & $22(2.1 \%)$ & $8(1.6 \%)$ & \\
\hline Caucasian & $486(46.1 \%)$ & 264 (52.3\%) & \\
\hline Hispanic & $147(14.0 \%)$ & 65 (12.9\%) & \\
\hline Other & 271 (25.7\%) & $123(24.4 \%)$ & \\
\hline Missing data & $164(15.6 \%)$ & 57 (11.3\%) & \\
\hline \multicolumn{4}{|l|}{ Passive smoking exposure } \\
\hline Number exposed & $166(15.7 \%)$ & 67 (13.3\%) & 0.22 \\
\hline Cigarettes per day & $0[0-0]$ & $0[0-0]$ & 0.23 \\
\hline Weight (kilograms) & $35[25.1-50]$ & 35 [21.2-50] & 0.89 \\
\hline Height (centimeters) & $140[126-154]$ & 140 [128-157] & 0.17 \\
\hline Allergic rhinitis diagnosis & $837(79.4 \%)$ & 199 (39.4\%) & $<0.001$ \\
\hline Food allergy diagnosis & $240(22.8 \%)$ & $79(15.6 \%)$ & 0.002 \\
\hline IgE sensitization & 792 (75.1\%) & 201 (39.8\%) & $<0.001$ \\
\hline Other chronic disease & $176(16.7 \%)$ & $76(15.1 \%)$ & 0.45 \\
\hline $\begin{array}{l}\text { Had flu vaccine in the previous } \\
\text { year }\end{array}$ & 402 (38.1\%) & $135(26.7 \%)$ & $<0.001$ \\
\hline
\end{tabular}

Note: Bold: Statistically significant between-group differences. 
TABLE 2 Asthma severity and asthma treatment adherence in the asthma group

\begin{tabular}{lc} 
Asthma severity & \\
Intermittent & $296(28.1 \%)$ \\
Mild persistent & $351(33.3 \%)$ \\
Moderate persistent & $291(27.6 \%)$ \\
Severe persistent & $111(10.5 \%)$ \\
Unknown & $5(0.5 \%)$ \\
\hline Treatment adherence & \\
Always as prescribed & $551(52.3 \%)$ \\
Sometimes not taken & $282(26.8 \%)$ \\
Often not taken & $41(3.9 \%)$ \\
Never taken & $106(10.1 \%)$ \\
Unknown & $74(7.0 \%)$ \\
\hline
\end{tabular}

TABLE 3 Change in the frequency of acute events during the pandemic, compared to 2019 among children with asthma and controls

\begin{tabular}{|c|c|c|c|}
\hline \multirow[b]{2}{*}{ Acute event } & \multicolumn{2}{|c|}{$\begin{array}{l}\text { Change in frequency } \\
\text { from } 2019\end{array}$} & \multirow{2}{*}{$\begin{array}{l}\text { Between-group } \\
\text { difference }\end{array}$} \\
\hline & Asthma & Control & \\
\hline URTI & $\downarrow$ & $\downarrow$ & $\begin{array}{l}\text { More pronounced } \\
\text { decrease in } \\
\text { control }\end{array}$ \\
\hline LRTI & - & $\uparrow$ & - \\
\hline Pyrexia & $\downarrow$ & $\downarrow$ & - \\
\hline Emergency visit & $\downarrow$ & - & - \\
\hline Hospital admission & $\downarrow$ & - & - \\
\hline $\begin{array}{l}\text { Need for additional } \\
\text { asthma } \\
\text { treatment }\end{array}$ & $\uparrow$ & NR & NR \\
\hline Acute asthma & $\downarrow$ & NR & NR \\
\hline $\begin{array}{l}\text { Hospitalization for } \\
\text { acute asthma }\end{array}$ & $\downarrow$ & NR & NR \\
\hline
\end{tabular}

Note: Between-group differences in the frequency of events were assessed using generalized linear regression analysis.

The strongest predictor for each type of acute events was the number of such events experienced by the participants during the preceding year ( $p<0.001$ for all analyses). In addition, older age was associated with a decreased risk of pyrexia $(p=0.025)$, while the race of the participants was also associated with the frequency of these events.

\subsubsection{Impact of the pandemic on the} frequency of the acute events, compared to the preceding year

Next, using paired statistics, we compared the frequency of each acute event during the pandemic, compared to the preceding year (Tables 3 and 4). Children with asthma experienced fewer URTIs, episodes of pyrexia, emergency visits, hospital admissions, asthma attacks, and hospitalizations due to asthma during the pandemic, compared to the preceding year. No differences were observed in the frequency of LRTIs during versus before the pandemic.

On the other hand, the pandemic did not appear to impact the frequency of emergency visits or hospital admissions of non-asthmatic controls. In this group, we observed a decreased frequency of URTIs and episodes of pyrexia, but also a significantly increased risk of LRTIs during the pandemic.

\subsubsection{Asthma control during the pandemic}

We then compared asthma control during versus before the pandemic (Table 5). A validated asthma control tool was used, following the local practice in every participating center, to ensure the availability of a measurement of the same tool during the pandemic and one during 2019. At least two asthma control measures (during and before the pandemic) were available for $90.9 \%$ of participants in the asthma group. ACT was used in 756 (78.9\%) of these children, while $C A C T, A C Q$, or CASI was used in the remaining cases.

Improved or unchanged asthma control during pandemic was reported by $90.2 \%$ of the participants, while only $9.8 \%$ reported worse asthma control. Moreover, $65.9 \%$ experienced an improvement. Importantly, one in three children with asthma (33.2\%) reported an improvement in control that exceeded the minimal clinically important difference of the test used.

Given the seasonal differences in asthma control, we conducted a sensitivity analysis where we only included historical asthma control measurements conducted during the same months with the first months of the pandemic (March-June 2019), with consistent findings (Table 5).

\subsection{Analyses of subgroups}

\subsection{1 | Pulmonary function during the pandemic}

Pulmonary function during the pandemic compared to 2019 was evaluated in a subgroup of asthma children with available data (Table 6). Adequate measurements of pre-bronchodilatation $\mathrm{FEV}_{1}$, post-bronchodilatation $\mathrm{FEV}_{1}$, and PFR were available in 155, 90, and 106 children, respectively. Paired analyses suggested prebronchodilatation $\mathrm{FEV}_{1}$ and PFR were significantly improved during the pandemic, while there was also a non-significant trend for improved post-bronchodilatation $\mathrm{FEV}_{1}$.

In a sensitivity analysis only including historical pulmonary function evaluated during the same months with the pandemic (MarchJune 2019), pre-bronchodilatation $\mathrm{FEV}_{1}$ was significantly improved during the pandemic, while the remaining measures showed nonsignificant, numerical improvements. 
TAB LE 4 Acute events observed during 2019 and during the pandemic

\begin{tabular}{|c|c|c|c|c|c|c|c|}
\hline \multirow[b]{2}{*}{ Acute events } & \multicolumn{3}{|c|}{ Children with asthma } & \multicolumn{3}{|l|}{ Controls } & \multirow[b]{2}{*}{$\begin{array}{l}\text { Between-group } \\
\text { differences }\end{array}$} \\
\hline & 2019 & Pandemic & $\begin{array}{l}\text { Frequency change } \\
\text { during pandemic }\end{array}$ & 2019 & Pandemic & $\begin{array}{l}\text { Frequency change } \\
\text { during pandemic }\end{array}$ & \\
\hline URTI & $\begin{array}{l}2[1-4] \\
81.6 \%\end{array}$ & $\begin{array}{l}0[0-1] \\
30.9 \%\end{array}$ & $\begin{array}{l}p<0.001 \\
73 \text { fewer }^{*}\end{array}$ & $\begin{array}{l}2[0-3] \\
71.3 \%\end{array}$ & $\begin{array}{l}0[0-1] \\
26.1 \%\end{array}$ & $\begin{array}{l}p<0.001 \\
35 \text { fewer }^{*}\end{array}$ & $\begin{aligned} p= & 0.005 \\
& \text { favoring } \\
& \text { control }\end{aligned}$ \\
\hline LRTI & $\begin{array}{l}0[0-1] \\
28.8 \%\end{array}$ & $\begin{array}{l}0[0-0] \\
12.1 \%\end{array}$ & $p=0.12$ & $\begin{array}{l}0[0-0] \\
16.8 \%\end{array}$ & $\begin{array}{l}0[0-0] \\
9.1 \%\end{array}$ & $\begin{array}{l}p<0.001 \\
18 \text { more }^{*}\end{array}$ & $p=0.09$ \\
\hline Pyrexia & $\begin{array}{l}0[0-2] \\
52.4 \%\end{array}$ & $\begin{array}{l}0[0-0], \\
17.2 \%\end{array}$ & $\begin{array}{l}p<0.001 \\
24 \text { fewer }^{*}\end{array}$ & $\begin{array}{l}0[0-2] \\
51.5 \%\end{array}$ & $\begin{array}{l}0[0-0] \\
15.8 \%\end{array}$ & $\begin{array}{l}p<0.001 \\
20 \text { fewer }^{*}\end{array}$ & $p=0.08$ \\
\hline Emergency visit & $\begin{array}{l}0[0-1] \\
34.4 \%\end{array}$ & $\begin{array}{l}0[0-0] \\
11.0 \%\end{array}$ & $\begin{array}{l}p<0.001 \\
9 \text { fewer }^{*}\end{array}$ & $\begin{array}{l}0[0-0], \\
20.0 \%\end{array}$ & $\begin{array}{l}0[0-0] \\
8.5 \%\end{array}$ & $p=0.79$ & $p=0.31$ \\
\hline Hospital admission & $\begin{array}{l}0[0-0] \\
13.1 \%\end{array}$ & $\begin{array}{l}0[0-0], \\
2.0 \%\end{array}$ & $\begin{array}{l}p<0.001 \\
17 \text { fewer }^{*}\end{array}$ & $\begin{array}{l}0[0-0] \\
5.5 \%\end{array}$ & $\begin{array}{l}0[0-0], \\
1.8 \%\end{array}$ & $p=0.29$ & $p=0.08$ \\
\hline $\begin{array}{l}\text { Need for additional } \\
\text { treatment }\end{array}$ & $\begin{array}{l}2[0-4] \\
74.0 \%\end{array}$ & $\begin{array}{l}0[0-1] \\
29.5 \%\end{array}$ & $\begin{array}{l}<0.001 \\
165 \text { more }\end{array}$ & & & & \\
\hline Acute asthma & $\begin{array}{l}0[0-1] \\
40.7 \%\end{array}$ & $\begin{array}{l}0[0-0] \\
9.6 \%\end{array}$ & $\begin{array}{l}p<0.001 \\
31 \text { fewer }^{*}\end{array}$ & & & & \\
\hline $\begin{array}{l}\text { Hospitalization for } \\
\text { acute asthma }\end{array}$ & $\begin{array}{l}0[0-0], \\
9.8 \%\end{array}$ & $\begin{array}{l}0[0-0], \\
1.2 \%\end{array}$ & $\begin{array}{l}p<0.001 \\
9 \text { fewer }^{*}\end{array}$ & & & & \\
\hline
\end{tabular}

Note: Presented as median [percentiles 25-75], and the percentage of participants experiencing at least one event in the respective observation period. Between-group differences assessed using generalized linear regression analysis.

*Events per 100 participants per year.

Bold: Statistically significant differences.

TABLE 5 Change in asthma control during the pandemic, compared to 2019

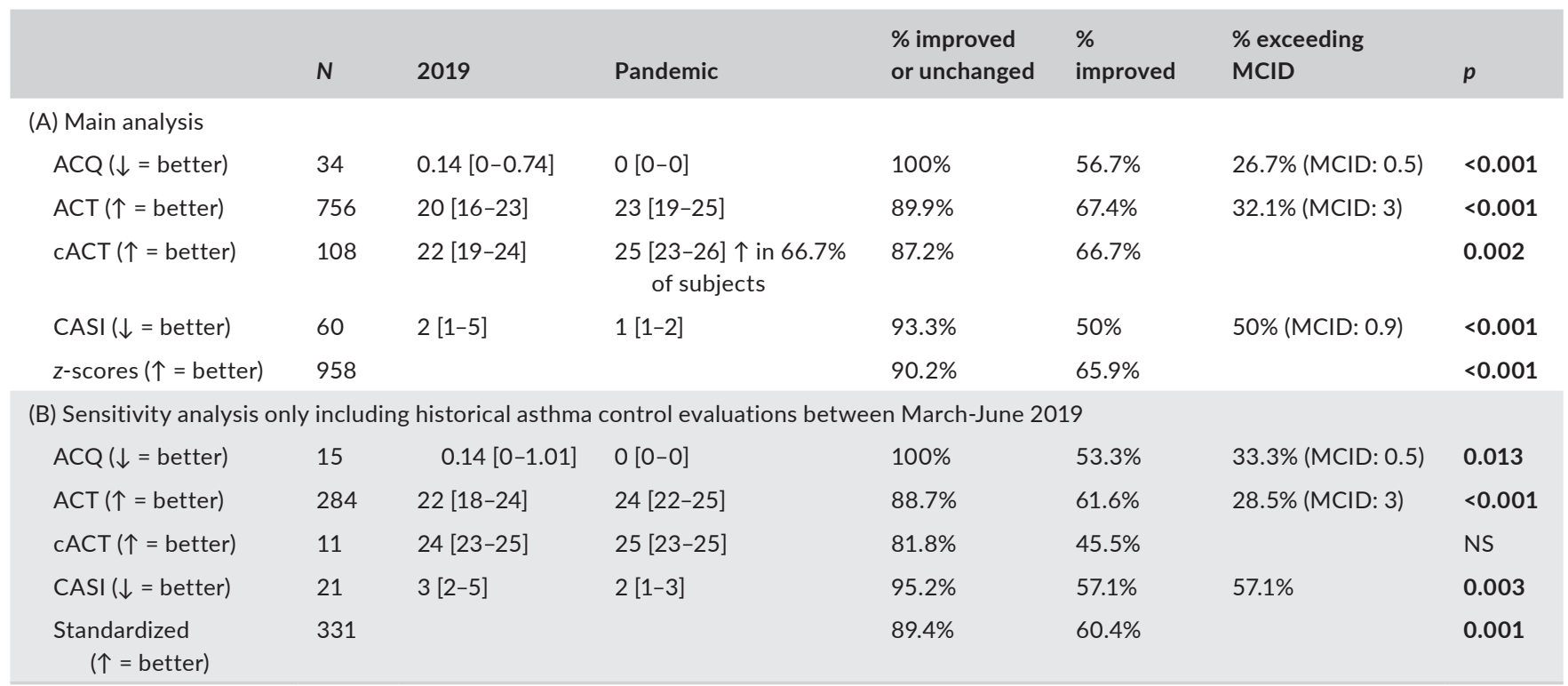

Note: Presented as median [percentiles 25-75. MCID: Minimal Clinically Important Difference. (A) Main analysis. (B) Sensitivity analysis only including historical asthma control evaluations between March-June 2019.

\subsection{2 | Subgroup analysis only including countries that were more severely hit by the pandemic}

In this subgroup analysis, all previously described analyses were repeated, including data from participating centers from countries that were more severely hit by the pandemic ( $>200$ deaths per million of inhabitants by $13 / 07 / 2020)$. More specifically, we included data from France, Italy, Mexico, Spain, UK, and the USA. This subgroup analyses, which involved 597 children with asthma and 298 non-asthmatic controls, yielded consistent results with the main analyses (Tables S2-S6). 
WILEY-Allergy

$\begin{array}{lcccc}\begin{array}{l}\text { Pulmonary function test } \\ \text { Main analysis }\end{array} & N & \text { Mean 2019 } & \text { Mean pandemic } & p \text {-value } \\ \begin{array}{l}\text { FEV1 } \\ \quad \text { pre-bronchodilatation } \\ \text { FEV1 post- } \\ \quad \text { bronchodilatation }\end{array} & 155 & 94.5 \%(15.1 \%) & 98.4 \%(16.6 \%) & <0.001 \\ \begin{array}{l}\text { PFR } \\ \begin{array}{l}\text { Sensitivity analysis only including historical asthma control evaluations between March-June } \\ 2019\end{array}\end{array} & 90 & 100.6 \%(14.6 \%) & 104.0 \%(19.2 \%) & 0.055 \\ \begin{array}{l}\text { FEV1 } \\ \quad \text { pre-bronchodilatation }\end{array} & 63 & 93.2 \%(12.0 \%) & 97.4 \%(15.2 \%) & 0.046 \\ \begin{array}{l}\text { FEV1 post- } \\ \text { bronchodilatation }\end{array} & 38 & 98.3 \%(12.8 \%) & 103.5 \%(22.5 \%) & 0.167 \\ \begin{array}{l}\text { PFR } \\ \quad\end{array} & 39 & 121.8 \%(106.5 \%) & 128.7 \%(106.6 \%) & 0.141\end{array}$

TABLE 6 Change in pulmonary function during the pandemic, compared to 2019. Presented as mean (SD)

\section{4 | DISCUSSION}

\section{1 | Key results}

In the multinational PeARL childhood asthma cohort, we evaluated the impact of the COVID-19 pandemic on asthma activity. During the pandemic, children with asthma experienced improved disease control (two thirds of the patients), as evidenced by improved scores in validated asthma control measures (>MCID in one third), fewer asthma attacks, fewer hospitalizations, and improved pulmonary function. The multifaceted etiology of this observation may include the avoidance of major asthma triggers including outdoor allergens, viral infections, physical exercise, and air pollution, due to social distancing, home sheltering, and reduced school days.,12,20-23 Increased treatment adherence during the pandemic ${ }^{24}$ could have also contributed. While our compliance data were self-reported and not objectively observed, we did find high adherence levels during the pandemic in our cohort. However, along with these "protective" effects of the pandemic, children were also more exposed to indoor allergens and pollutants and possibly adverse psychological factors and there is a chance this could have precipitated worse asthma control, nevertheless, in a minority of children $(1 / 10$ children in our cohort). Finally, during the pandemic we observed an increase in the frequency of URTIs among asthmatic children, compared to controls. While this could be considered consistent with previous findings suggesting COVID-19 infection may only be associated with limited upper respiratory symptoms in children, ${ }^{25}$ it is more likely to reflect an increased attention given to minor symptoms or heightened awareness due to the COVID-19 pandemic.

\section{2 | Interpretation}

The interplay between asthma and COVID-19 infection is being extensively investigated. Several studies explored the prevalence of asthma among children and adults with confirmed COVID-19 infection and failed to find an increased risk of contracting the infection or of adverse outcomes among asthmatic patients. ${ }^{26,27}$ A recent review with meta-analysis done in adults with COVID-19 (744 asthmatic and 8151 non-asthmatic) showed that the presence of asthma had no significant effect on mortality $\left(O R=0.96\right.$ [0.70-1.30], $I^{2}=0 \%$, $p=0.79$ ), duration of hospitalization, or the risk of ICU admission. ${ }^{28}$ However, COVID-19 infection was significantly underdiagnosed during the initial months of the pandemic due to limited availability of diagnostic tests that led most countries to recommend home isolation without testing in case of non-severe symptoms consistent with COVID-19. The PeARL asthma cohort is the first large, multinational cohort to demonstrate that children with asthma do not experience more frequent events of disease deterioration during this period, including in countries with an increased COVID-19 burden. In contrast, most outcomes were improved. These findings strongly reinforce the need and potential of compliance to treatment, ${ }^{29,30}$ as well as the prospect of improved outcomes with environmental control in asthma, an area of some discrepancy. ${ }^{31}$

The role of different viruses as asthma attack triggers has been investigated extensively. While rhinoviruses represent the main viral trigger of attacks, coronaviruses also trigger asthma attacks, albeit less frequently. ${ }^{32}$ However, and in line with our findings, the outbreak of SARS in Singapore and Hong Kong was not associated with increased asthma attacks in children. ${ }^{33,34}$ On the contrary, and in line with our results, the incidence of acute respiratory tract infections and acute asthma attacks declined dramatically, likely due to the closure of schools for a period of time, stepped-up public hygiene measures and the use of facemasks. ${ }^{33,34}$

Despite that we did not have access to serology or exposure data, the improved outcomes among asthmatic children during SARS/COVID-19 epidemics are not incompatible with the hypothesis of a protective effect of asthma against COVID-19. This hypothesis is based on several observations, including changed in the immune response or decreased risk secondary to chronic medications such as inhaled corticosteroids (ICS). In vitro models have shown that ICS may suppress both coronavirus replication and cytokine production. ${ }^{35,36}$ Analysis of induced sputum samples in a wellcharacterized cohort of adults with severe asthma found reduced 
ACE2 (angiotensin-converting enzyme 2) and TMPRSS2 (transmembrane protease serine 2) gene expression among patients taking ICS, and especially among those on higher doses ${ }^{37}$; and we know ACE2 and TMPRSS2 mediate SARS-CoV-2 cell infection. Similarly, a recent study done in children and adults showed that patients with asthma and respiratory allergies had reduced ACE2 gene expression in airway cells, suggesting a potential mechanism of reduced COVID-19 risk. $^{11}$

\section{3 | Limitations and strengths}

This study was based on an audit and, therefore, we did not have access to COVID-19 serology or details on the exposure history of the children or their parents, which would have been informative.

Evaluation of the frequency of acute events during the pandemic is challenging, but we believe our methodology was rigorous. Firstly, the accuracy of parent-reported frequency of acute events has been previously validated. ${ }^{38}$ We assumed a potential under-reporting of acute events during 2019, due to recall bias; however, we do not anticipate between-group differences in this bias. In addition, potential under-reporting of acute events prior to the pandemic would have led to an overestimation of the relative risk during the pandemic. Since we did not find an increased risk, we suggest the impact of recall bias was minimal.

During the first wave of the pandemic, many patients hesitated to attend face-to-face follow-up visits, suggesting that potential participants may have been missed. ${ }^{10}$ However, all participating centers offered alternative follow-up options, including phone call or teleconference facilities. Moreover, we would anticipate that patients with less controlled asthma, or those experiencing acute events are more likely to adhere to their follow-up visits or phone calls. However, study participants in the PeARL cohort reported in general better asthma control and less acute events during the pandemic. Therefore, it is unlikely that potential bias from missing wellcontrolled patients had a significant impact in our findings.

For estimating the duration of the pandemic, we considered the onset of the pandemic to coincide with the first fatality in each respective country. This usually followed a few days to weeks after the identification of the first case. We chose this time point as an objective marker that could better identify the onset of the impact of the pandemic in each community. Since we were inquiring for acute episodes during the epidemic, we wanted to avoid a potential underestimation of the frequency of the events that could have been caused by accounting for a wider time period of the epidemic.

Extrapolating an annualized asthma attack rate based on the events that were observed during the pandemic is complicated by the seasonal variability of asthma attacks. ${ }^{39,40}$ However, numerous high-quality studies demonstrate a peak in childhood asthma attack during autumn and schools reopening, which is counterbalanced by a low frequency during summer. ${ }^{32,41}$ Interestingly, these studies consistently show that the frequency of asthma attacks and asthma hospitalizations during spring and early summer levels with the median frequency of asthma attacks throughout the year. ${ }^{19,20}$ The study period coincided with these months, suggesting that the frequency of acute events equals to their frequency throughout the year. This observation enhances our confidence on the accuracy of our annualized estimates and our findings, however, the limited observation period during the pandemic remains a limitation of this study.

The over-representation of atopic diseases in the control group shall be mentioned as a potential limitation, but it has been accounted for in our analyses. Finally, different validated questionnaires were used for assessing asthma control across the study centers, depending on the availability of historic measurements, to allow for paired comparisons. While the results of different tools are not directly comparable, our study revealed consistent results in the subgroups evaluated with different tools. On the other hand, the extensive, multinational study population with a good geographic balance across 4 continents, was a major strength of our study, increasing our confidence in our findings.

\section{5 | CONCLUSION}

Overall, this analysis of the PeARL childhood asthma cohort revealed improved health and asthma activity during the COVID-19 pandemic, probably associated with decreased exposure to asthma triggers and increased treatment adherence. It also demonstrated that during the pandemic, children with predominantly mild to moderate atopic asthma did not suffer from an increase in the frequency of acute episodes that could represent COVID-19 infection.

\section{ACKNOWLEDGEMENTS}

This study was supported by the Respiratory Effectiveness Group (REG). REG has received support from AstraZeneca, Novartis, and Sanofi for continued work on PeARL. AGM was supported by the National Institute of Health Research Manchester Biomedical Research Centre (NIHR Manchester BRC). We thank Mrs Maria Kritikou for excellent administrative support of the study.

\section{CONFLICT OF INTEREST}

This study was supported by the Respiratory Effectiveness Group (REG). REG has received support from AstraZeneca, Novartis, and Sanofi for continued work on PeARL. TJ reports grants from The Paulo Foundation, Helsinki, Finland. MT reports grants from The Sigrid Juselius Foundation, Helsinki, Finland, during the conduct of the study. None of the other authors had any conflicts of interest directly related to this work. AND, AF, KN,EH, LN-B, WP, ZC, WF, GW, LG-M, ZAW-S, YRHV, CFPB, DRY, CS, PLR, PS, RA-T, J-CD, JL, TR, DY, AMR, KW, RE-O, JAC-R, AG, CM, AILG, MM-A, EMNR, MKN, $V F$, and $E R-Z$ do not declare any conflicts of interest outside the submitted work either. NGP reports personal fees from ALK, Novartis, Nutricia, HAL, Menarini/FAES Farma, Sanofi, Mylan/MEDA, Biomay, AstraZeneca, GSK, MSD, ASIT BIOTECH, and Boehringer Ingelheim; grants from Gerolymatos International SA and Capricare outside the 
submitted work. AGM reports grants from Boehringer Ingelheim outside the submitted work. AC reports personal fees from Novartis, Thermo Fisher Scientific, Philips, Sanofi, Stallergenes Greer, AstraZeneca, outside the submitted work. AD reports personal fees and other from Novartis, ALK, MYLAN, GSK,CHIESI, Astra Zeneca, DBV technologies, grants and personal fees from Stallergenes Greer, personal fees from Almmune, Zambon, Boehringer Ingelheim, Nestlé HealthScience, other from Nutricia, outside the submitted work. IA reports and Associate Editor Allergy journal. PXreports personal fees from Nutricia, Nestle, Menarini, Uriach, Novartis PharmaAG, and GlaxoSmithkline outside the submitted work. CM reports personal fees from Novartis, GSK, ThermoFisher, Boehringer Ingelheim, outside the submitted work.

\section{AUTHOR CONTRIBUTIONS}

NGP: Study conception and study design. AGM and NGP: Data analysis. All authors: Data collection, interpretation of the findings, and critical revision of the manuscript.

\section{ORCID}

Nikolaos G. Papadopoulos (D) https://orcid.

org/0000-0002-4448-3468

Alexander G. Mathioudakis (D) https://orcid.

org/0000-0002-4675-9616

Antoine Deschildre (D) https://orcid.org/0000-0003-2006-7221

Gary Wong (D) https://orcid.org/0000-0001-5939-812X

Paraskevi Xepapadaki (D) https://orcid.org/0000-0001-9204-1923

loana Agache (D) https://orcid.org/0000-0001-7994-364X

Zhimin Chen (D) https://orcid.org/0000-0003-4267-9579

Rasha El-Owaidy (D) https://orcid.org/0000-0002-5609-4160

Wojciech Feleszko (D) https://orcid.org/0000-0001-6613-2012

Alessandro Fiocchi (iD https://orcid.org/0000-0002-2549-0523

Mário Morais-Almeida (D) https://orcid.org/0000-0003-1837-2980

\section{REFERENCES}

1. Wu H, Zhu H, Yuan C, et al. Clinical and immune features of hospitalized pediatric patients with coronavirus disease 2019 (COVID-19) in Wuhan, China. JAMA Netw Open. 2020;3(6):e2010895. https://doi. org/10.1001/jamanetworkopen.2020.10895

2. Shekerdemian LS, Mahmood NR, Wolfe KK, et al. Characteristics and outcomes of children with coronavirus disease 2019 (COVID-19) infection admitted to US and Canadian Pediatric Intensive Care Units. JAMA Pediatr. 2020;174:868-873.In press.

3. Viner RM, Mytton OT, Bonell C, et al. Susceptibility to SARS-CoV-2 infection among children and adolescents compared with adults: a systematic review and meta-analysis. JAMA Pediatr. 2020;175:143156. https://doi.org/10.1001/jamapediatrics.2020.4573

4. Ioannou GN, Locke E, Green P, et al. Risk factors for hospitalization, mechanical ventilation, or death among 10131 US veterans with SARS-CoV-2 infection. JAMA Netw Open. 2020;3(9):e2022310. https://doi.org/10.1001/jamanetworkopen.2020.22310

5. Grasselli G, Greco M, Zanella A, et al. Risk factors associated with mortality among patients with COVID-19 in intensive care units in Lombardy, Italy. JAMA Intern Med. 2020;180:1345-1355.In press.

6. Williamson EJ, Walker AJ, Bhaskaran K, et al. Factors associated with COVID-19-related death using OpenSAFELY. Nature. 2020;584(7821):430-436.
7. CDC COVID-19 Response Team. Coronavirus disease 2019 in children-United States. February 12-April 2, 2020. MMWR Morb Mortal Wkly Rep. 2020;69(14):422-426.

8. Zhang JJ, Dong X, Cao YY, et al. Clinical characteristics of 140 patients infected with SARS-CoV-2 in Wuhan, China. Allergy. 2020;75(7):1730-1741.

9. National Institute for Health and Care Excellence (NICE). COVID-19 rapid guideline: severe asthma. 2020. NICE guideline [NG166]. https://www.nice.org.uk/guidance/ng166. Accessed 13 March 2021.

10. Papadopoulos NG, Custovic A, Deschildre A, et al. Impact of COVID-19 on pediatric asthma: Practice adjustments and disease burden. J Allergy Clin Immunol Pract. 2020;8(8):2592-2599. https:// doi.org/10.1016/j.jaip.2020.06.001

11. Jackson DJ, Busse WW, Bacharier LB, et al. Association of respiratory allergy, asthma, and expression of the SARS-CoV-2 receptor ACE2. J Allergy Clin Immunol. 2020;146(1):203. https://doi. org/10.1016/j.jaci.2020.04.009

12. Krivec U, Kofol Seliger A, Tursic J. COVID-19 lockdown dropped the rate of paediatric asthma admissions. Arch Dis Child. 2020;105:809-810.

13. Taquechel K, Diwadkar AR, Sayed S, et al. Pediatric asthma health care utilization, viral testing, and air pollution changes during the COVID-19 pandemic. J Allergy Clin Immunol Pract. 2020;8(10):3378. https://doi.org/10.1016/j.jaip.2020.07.057

14. Mathioudakis AG, Custovic A, Deschildre A, et al. Research Priorities in Pediatric Asthma: Results of a Global Survey of Multiple Stakeholder Groups by the Pediatric Asthma in Real Life (PeARL) Think Tank. J Allergy Clin Immunol Pract. 2020;8(6):1953. https://doi.org/10.1016/j.jaip.2020.01.059

15. von Elm E, Altman DG, Egger M, et al. The strengthening the reporting of observational studies in epidemiology (STROBE) statement: guidelines for reporting observational studies. J Clin Epidemiol. 2008;61(4):344-349.PMID: 18313558.

16. Nathan RA, Sorkness CA, Kosinski M, et al. Development of the asthma control test: a survey for assessing asthma control. J Allergy Clin Immunol. 2004;113(1):59-65. https://doi.org/10.1016/j. jaci.2003.09.008

17. Liu AH, Zeiger R, Sorkness $C$, et al. Development and crosssectional validation of the childhood asthma control test. J Allergy Clin Immunol. 2007;119(4):817-825. https://doi.org/10.1016/j. jaci.2006.12.662

18. Juniper EF, Bousquet J, Abetz L, Bateman ED, GOAL Committee. Identifying 'well-controlled' and 'not well-controlled' asthma using the Asthma Control Questionnaire. Respir Med. 2006;100(4):616621. https://doi.org/10.1016/j.rmed.2005.08.012

19. Wildfire JJ, Gergen PJ, Sorkness CA, et al. Development and validation of the Composite Asthma Severity Index-an outcome measure for use in children and adolescents. J Allergy Clin Immunol. 2012;129(3):694-701. https://doi.org/10.1016/j.jaci.2011.12.962

20. Niespodziana K, Borochova K, Pazderova P, et al. Toward personalization of asthma treatment according to trigger factors. J Allergy Clin Immunol. 2020;145:1529-1534.

21. Eguiluz-Gracia I, Mathioudakis AG, Bartel S, et al. The need for clean air: the way air pollution and climate change affect allergic rhinitis and asthma. Allergy. 2020;75:2170-2184.

22. Taquechel K, Diwadkar AR, Sayed S, et al. Pediatric asthma healthcare utilization, viral testing, and air pollution changes during the COVID-19 Pandemic. J Allergy Clin Immunol Pract. 2020;8(10):3378. https://doi.org/10.1016/j.jaip.2020.07.057

23. Chavasse R, Almario A, Christopher A, Kappos A, Shankar A. The indirect impact of COVID-19 on children with asthma. Arch Bronconeumol. 2020;56(11):768-769. https://doi.org/10.1016/j. arbres.2020.07.00

24. Bousquet J, Jutel M, Akdis CA, et al. ARIA-EAACl statement on asthma and COVID-19 (June 2, 2020). Allergy. 2020;76(3):689-697. 
25. Lu X, Zhang L, Du H, Zhang J, Li YY, Qu J. SARS-CoV-2 infection in children. N Engl J Med. 2020;382(17):1663-1665. https://doi. org/10.1056/NEJMc2005073

26. Wang Y, Ao G, Qi X, Xie B. The association between COVID-19 and asthma: a systematic review and meta-analysis. Clin Exp Allergy. 2020;50(11):1274-1277.[In press].

27. Hartmann-Boyce J, Gunnell J, Drake J, et al. Asthma and COVID-19: review of evidence on risks and management considerations. BMJ Evid Based Med. 2020. https://doi.org/10.1136/bmjeb $\mathrm{m}-2020-111506$

28. Wang Y, Chen J, Chen W, et al. Does asthma increase the mortality of patients with COVID-19? A systematic review and meta-analysis. Int Arch Allergy Immunol. 2020;22:1-7. https://doi. org/10.1159/000510953

29. Vervloet M, van Dijk L, Spreeuwenberg P, et al. The relationship between real-world inhaled corticosteroid adherence and asthma outcomes: a multilevel approach. J Allergy Clin Immunol Pract. 2020;8(2):626-634.

30. Levin M, Ansotegui IJ, Bernstein J, et al. Acute asthma management during SARS-CoV2-pandemic 2020. World Allergy Organ J. 2020;13(5):100125.

31. Murray CS, Foden P, Sumner H, Shepley E, Custovic A, Simpson A. Preventing severe asthma exacerbations in children. A randomized trial of mite-impermeable bedcovers. Am J Respir Crit Care Med. 2017;196(2):150-158.

32. Deschildre A, Pichavant M, Engelmann I, et al. Virus-triggered exacerbation in allergic asthmatic children: neutrophilic airway inflammation and alteration of virus sensors characterize a subgroup of patients. Respir Res. 2017;18(1):191. https://doi.org/10.1186/s1293 1-017-0672-0

33. Van Bever HP, Chng SY, Goh DY. Childhood severe acute respiratory syndrome, coronavirus infections and asthma. Pediatr Allergy Immunol. 2004;15(3):206-209. https://doi. org/10.1111/j.1399-3038.2004.00137.x

34. Hon $\mathrm{KL}$, Leung $\mathrm{CW}$, Cheng WT, et al. Clinical presentations and outcome of severe acute respiratory syndrome in children. Lancet. 2003;361(9370):1701-1703. https://doi.org/10.1016/s01406736(03)13364-8

35. Yamaya M, Nishimura H, Deng $X$, et al. Inhibitory effects of glycopyrronium, formoterol, and budesonide on coronavirus HCoV-229E

\section{APPENDIX 1}

\section{PeARL collaborators}

Anna Alekseeva, Bethan Almeida, Maud Andre, Polina Arimova, Aurore Blonde, Amparito Cunningham, Sofia Da Mota, Kamilla Efendieva, Vera Kalugina, Sébastien Kiefer, Anais Klein, Chrystopherson Gengyny Caballero López, Juan Jesús Ríos López, Caroline Moratellti, Miguel Fuentes Pérez, Meryl Simermann, José Sergio Papaqui Tapia, Aurelie Tatopoulos, Elena Vishneva, Konstantin Volkov.

\section{PeARL Think Tank}

Ioana Agache, Zeinab Awad El-Sayed, Leonard Bacharier, Matteo Bonini, Jose Castro-Rodriguez, Zhimin Chen, Timothy Craig, Adnan Custovic, Antoine Deschildre, Zuzana Diamant, replication and cytokine production by primary cultures of human nasal and tracheal epithelial cells. Respir Investig. 2020;58(3):155168. https://doi.org/10.1016/j.resinv.2019.12.005

36. Matsuyama S, Kawase M, Nao N, et al. The inhaled corticosteroid ciclesonide blocks coronavirus RNA replication by targeting viral NSP15. bioRxiv. 2020. https://doi.org/10.1101/2020.03.11.987016

37. Peters MC, Sajuthi S, Deford P, et al. COVID-19-related genes in sputum cells in asthma. Relationship to demographic features and corticosteroids. Am J Respir Crit Care Med. 2020;202(1):83-90. https://doi.org/10.1164/rccm.202003-08210C

38. Megremis S, Niespodziana K, Cabauatan C, et al. Rhinovirus speciesspecific antibodies differentially reflect clinical outcomes in health and asthma. Am J Respir Crit Care Med. 2018;198(12):1490-1499.

39. Johnston NW, Johnston SL, Norman GR, Dai J, Sears MR. The September epidemic of asthma hospitalization: school children as disease vectors. J Allergy Clin Immunol. 2006;117(3):557-562.

40. Gergen PJ, Mitchell H, Lynn H. Understanding the seasonal pattern of childhood asthma: Results from the national cooperative innercity asthma study (NCICAS). J Pediatr. 2002;141(5):631-636.

41. Teach SJ, Gergen PJ, Szefler SJ, et al. Seasonal risk factors for asthma exacerbations among inner-city children. J Allergy Clin Immunol. 2015;135(6):1465. https://doi.org/10.1016/j.jaci.2014.12.1942

\section{SUPPORTING INFORMATION}

Additional supporting information may be found online in the Supporting Information section.

How to cite this article: Papadopoulos NG, Mathioudakis AG, Custovic A, et al. Childhood asthma outcomes during the COVID-19 pandemic: Findings from the PeARL multinational cohort. Allergy. 2021;00:1-11. https://doi.org/10.1111/ all.14787
Francine M. Ducharme, Wojciech Feleszko, Alessandro Fiocchi, Luis Garcia-Marcos, James E. Gern, Anne Goh, Jonathan Grigg, Eckard H. Hamelmann, Gunilla Hedlin, Elham M. Hossny, Tuomas Jartti, Omer Kalayci, Alan Kaplan, Jon Konradsen, Piotr Kuna, Susanne Lau, Peter Le Souef, Robert F. Lemanske, Mika J Makela, Alexander G. Mathioudakis, Paolo M. Matricardi, René Maximiliano Gómez, Michael Miligkos, Mário Morais-Almeida, Clare Murray, Leyla Namazova-Baranova, Antonio Nieto Garcia, Nikolaos G. Papadopoulos, Wanda Phipatanakul, Paulo MC Pitrez, David Price, Petr Pohunek, Graham C. Roberts, Aziz Sheikh, Ioanna Tsiligianni, Steve Turner, Arunas Valiulis, Tonya Winders, Gary Wong, Paraskevi Xepapadaki, Osman M. Yusuf, Heather Zar. 